\title{
Assessment of microorganism activity as bio- preservatives for perishable food
}

\author{
Margarita Shevchenko ${ }^{1, *}$, Maria Zimina ${ }^{1}$, Stanislav Sukhikh ${ }^{1,2}$, Yegor Gromov ${ }^{2}$, and Elena \\ Zubareva $^{2}$ \\ ${ }^{1}$ Immanuel Kant Baltic Federal University, 14 A. Nevsky St., 236016 Kaliningrad, Russia \\ ${ }^{2}$ Kemerovo State University, 6 Krasnaya St., 650000 Kemerovo, Russia
}

\begin{abstract}
Analysis of the results of studying dynamics of microbiological indicators of perishable food (fresh tomatoes), shows that the control samples (fresh tomatoes without processing a preservative) on the 15 th day of storage at $4 \pm 2{ }^{\circ} \mathrm{C}$ exceeds the QMA\&OAMO index, on the 5 th day yeast already detected. The activity of yeasts and molds on the surface of tomatoes treated with Nisin is reduced compared with the control. It was found that the new isolated microorganisms synthesizing bacteriocins exhibit the highest bioconservation efficiency compared to nisin and control. It was shown that QMA\&OAMO does not exceed the maximum permissible value even at 35 days of storage, yeast and molds, E. coli group bacteria in $1.0 \mathrm{~g}$ and pathogenic microorganisms, including L. monocytogenes and Salmonella bacteria in $10.0 \mathrm{~g}$ were not detected in fresh tomatoes. As a result of the study of organoleptic quality indicators of perishable foods (fresh tomatoes), treated with selected strains of microorganisms (Bacillus subtilis, Lactobacillus rhamnosus, Pseudomonas putida and Psychrobacter immobilis), stored for 35 days at $4 \pm 2{ }^{\circ} \mathrm{C}$ revealed that fresh tomatoes on the 35 th day keep fresh, the fruit is clean, excessive moisture of fruits is not observed. Also fresh tomatoes were characterized by an edible degree of maturity. The taste and smell of the tomatoes were consistent with the botanical variety, while no extraneous taste and smell were observed. Keywords: bioconservatives, perishable food, bacteriocins, organoleptic properties.
\end{abstract}

\section{Introduction}

Microorganisms growing on food products cause varying degrees of change in food characteristics as a result of their metabolic activity. The processes resulting from the fill of food by with microorganisms can be both positive (fermentation) and lead to spoilage, causing economic losses, and foodborne diseases [1]. There are a number of factors that affect the behavior food microflora and are taken into account when choosing how to prepare, store and transport goods. These factors can be divided into two main groups - internal and external. Internal factors characterize the food itself, and external factors characterize the environment. The need to control the time and temperature of storage is determined by the possibility of contamination by pathogenic microorganisms and their subsequent growth,

*Corresponding author: elen.ulrich@mail.ru 
accompanied by toxins production. There are also implicit factors and treatment factors, in addition, their interaction is important [2].

Internal factors. The internal factors include water activity, $\mathrm{pH}$ value, nutrient content, presence of antimicrobial compounds and mechanical barriers to microbial invasion, and oxidation-reduction potential [1].

Microorganisms need water in an accessible form to grow. Controlling the moisture content of food is one of the oldest used preservation strategies. Food microbiologists generally describe the water need of microorganisms in terms of water activity (aw) of food or the environment. The presence of water is also necessary for chemical reactions in the cell and the transport of nutrients. Water activity is defined as the ratio of the water vapor pressure of food to the vapor pressure of pure water at the same temperature. The activity value of pure water is 1 , and completely dry substrate is 0 . The addition of various soluble substances reduces the water activity because they fix water. Examples are sodium chloride or sucrose $[3,4]$.

An important factor is the $\mathrm{pH}$ value. Microorganisms grow in the $\mathrm{pH}$ range of 1 to 11 . Mold fungi have the widest range, while bacteria have the narrowest [5]. Nonpathogenic bacteria are more resistant to acids than pathogenic bacteria (minimum $\mathrm{pH} 2.0-4.4$ for nonpathogenic group and 3.8-5.0 for pathogenic group). In general, yeasts and molds reproduce better in acidic environments, which include fruit. Vegetables, meat, poultry, fish, and dairy products have higher $\mathrm{pH}$ values and therefore are substrates for bacteria [6].

Thermal treatment of acidic foods includes pasteurization, while industrial sterilization is used for foods with low acid content. Both types of products may contain live bacterial spores after heat treatment. Those found in commercially sterilized foods are spores of thermophilic bacteria. The low $\mathrm{pH}$ of acidic foods prevents the germination of bacterial spores, while the spores of thermophilic bacteria in a low-acid environment cannot grow at temperatures below $30{ }^{\circ} \mathrm{C}$, which makes it necessary to store such foods at low temperatures [7].

Thus, foods containing simple sugars and free amino acids in high concentrations are more suitable for microbial growth [8]. Many types of bacteria, especially Gramm-negative bacteria such as Pseudomonas, Acinetobacter, Moraxella, Shewanella and Aeromonas, and pathogenic spore-forming bacteria such as Clostridium botulinum, are proteolytic and can grow well in protein-rich foods, leading to rapid spoilage or disease if consumed. (International Commission on Microbiological Specification for Foods, 2005). Carbohydrate-rich food can be used as a substrate by saccharolytes, which include bacteria of the genera Bacillus, Clostridium, Aeromonas, Pseudomonas, Leuconostoc and Enterobacter, as well as yeasts and molds [9]. Relatively few microorganisms, such as mold, yeast, and a few Gramm-negative bacteria, are capable of metabolizing fats. These include Pseudomonas spp., Flavobacterium spp., Saccharomycopsis lipolytica, Candida lipolytica, Penicillium spp. and Aspergillus spp. [10].

External factors. The external factors related to the environment in which food is stored include storage temperature, gas composition, and relative humidity in the atmosphere [1].

Microbial growth is the result of a series of chemical reactions and is therefore directly dependent on the environmental temperature. Microorganisms are capable of growing in a wide range of temperatures, from 0 to $100{ }^{\circ} \mathrm{C}$, but the range for each species is much narrower. In addition, different species have their own maximum, minimum, and optimum temperatures. As the temperature exceeds the minimum required for growth, the rate of chemical reactions in the cell increases and multiplication is accelerated, reaching a maximum at the optimal temperature. When the temperature exceeds the optimal temperature, metabolic reactions begin to slow down due to damage to enzymes and cell membranes [11]. As a result, the growth rate decreases rapidly and reaches zero. Microorganisms are divided into psychrophiles, mesophiles, and thermophiles in relation to temperature. The most dangerous for perishable products are prichophytes, these are capable 
of growing at low temperatures, including 0 to $7{ }^{\circ} \mathrm{C}$ [2]. This group of microorganisms is found in soil and water in regions with temperate climates. There are many bacteria and fungi that cause food spoilage and food poisoning [8]. Examples of such bacteria are Pseudomonas aeruginosa, Pseudomonas fluorescens, Leuconostoc mesenteroides and Lactobacillus sake. Cladosporium and Aspergillus strains were isolated from spoiled date fruit at the rutabaga stage that had been stored at $5{ }^{\circ} \mathrm{C}$ [9]. The yeast species Yarrowia lipolytica, Debaryomyces hansenii and Pichiambranifaciens were isolated from various chilled food products. Microorganisms capable of causing foodborne disease include the species L. monocytogenes, Y. enterocolitica and Aeromonas hydrophila [3].

One of the main criteria for the choice of selected microbial strains is the presence of antimicrobial properties, which are due to the formation of secondary metabolites and protein compounds known as bacteriocins.

The goal of this paper was to assess the activity of microorganisms as bioconservatives for perishable foods (fresh tomatoes).

\section{Materials and Methods}

The activity of the selected microorganisms as bioconservatives for perishable foodstuffs was assessed in this paper. For this purpose, perishable foods were treated with selected strains of microorganisms (Bacillus subtilis, Lactobacillus rhamnosus, Pseudomonas putida and Psychrobacter immobilis) and assessed the dynamics of microbiological indicators in accordance with the recommendations of MG 4.2.1847 "Sanitary and epidemiological assessment of the shelf life and storage conditions of food". In addition to the traditionally normalized QMA\&OAMO, coliform bacteria, pathogenic microorganisms, fresh vegetables when justifying the shelf life should be examined for the absence of St. acerus, to determine the number of yeasts and molds during storage. Control of microbiological indicators of perishable food treated with selected strains of microorganisms (Bacillus subtilis, Lactobacillus rhamnosus, Pseudomonas putida and Psychrobacter immobilis) and Nisin (food additive E234) was performed immediately after treatment, on 3, 5, 7, 15, 25, and 35 days at a storage temperature of $4 \pm 2^{\circ} \mathrm{C}$.

The quantity of mesophyll aerobic and optional-anaerobic microorganisms (QMA\&OAMO) was determined in accordance with GOST 10444.15-94; coliform bacteria - according to GOST 31747-2012); toxin-forming anaerobes - according to GOST 2856090; pathogenic microorganisms - according to GOST ISO 22118-2013 and GOST 320312012; Staphylococcus aureus bacteria - according to GOST 10444.2-94. For this purpose, the following laboratory equipment was used: laminar box class 2/type A BAVP-01"Laminar-S"-1,5 (Laminarnyye sistemy CJSC, Russia), thermostat Shaking Incubator LSI3016A (Daihan Labtech, South Korea), autoclave DGM-80 (Pharma Apparate Handel AG, Switzerland), upright microscope AxioScope A1 (Zeiss, Germany). During the research and development, commercially available reagents of domestic and imported production with a purity degree not lower than chempure were used.

The main criterion for a positive assessment of the validity of the food shelf life was the absence of negative dynamics of the whole complex of studied indicators, including:

1) the negative dynamics of microbiological indicators in product, characterized by the following criteria:

- non-compliance of standardized microbiological indicators with the established requirements in any of the test reference points under study;

- increase in the number of spoilage pathogens (yeasts and molds) more than twice as much as originally detected;

- detection of proteus bacteria in samples of products normalized by this indicator - in case of non-compliance with the standard; 
2) deterioration of organoleptic indicators in the dynamics of storage.

Fresh tomatoes were selected as perishable foods in order to evaluate the activity of selected microorganisms as bioconservatives for perishable foods.

Organoleptic and physicochemical properties of perishable foodstuffs (fresh tomatoes) treated with selected strains of microorganisms (Bacillus subtilis, Lactobacillus rhamnosus, Pseudomonas putida and Psychrobacter immobilis) that were stored for 35 days at $4 \pm 2{ }^{\circ} \mathrm{C}$ were studied. Organoleptic and physicochemical properties of perishable foods (fresh tomatoes) treated with selected strains of microorganisms (Bacillus subtilis, Lactobacillus rhamnosus, Pseudomonas putida and Psychrobacter immobilis) were studied at 35 days of storage.

\section{Results and Discussion}

The results of studying dynamics of microbiological indicators of perishable foods (fresh tomatoes) are presented in Table 1.

Table 1. The results of studying dynamics of microbiological indicators of perishable foods (fresh tomatoes)

\begin{tabular}{|c|c|c|c|c|c|}
\hline \multirow[b]{2}{*}{$\begin{array}{c}\text { Storage } \\
\text { duration, } \\
\text { days }\end{array}$} & \multicolumn{5}{|c|}{ Microbiological indicators } \\
\hline & $\begin{array}{c}\text { Coliform } \\
\text { bacteria in } \\
1.0 \mathrm{~g}\end{array}$ & $\begin{array}{c}\text { QMA\&OAM } \\
\text { O, CFU/g }\end{array}$ & $\begin{array}{c}\text { Pathogenic } \\
\text { microorganisms, } \\
\text { including } L . \\
\text { monocytogenes and } \\
\text { Salmonella bacteria } \\
\text { in } 10.0 \mathrm{~g}\end{array}$ & $\begin{array}{l}\text { St. aureus in } \\
1.0 \mathrm{~g}\end{array}$ & $\begin{array}{c}\text { Yeast and } \\
\text { molds, CFU/g }\end{array}$ \\
\hline \multicolumn{6}{|c|}{ Control (out of treatments) } \\
\hline $\begin{array}{c}0 \\
\text { (background) }\end{array}$ & - & $1.5 \cdot 10^{3}$ & - & - & - \\
\hline 3 & - & $3.3 \cdot 10^{3}$ & - & - & - \\
\hline 5 & - & $5.5 \cdot 10^{3}$ & - & - & 1.0 \\
\hline 7 & - & $5.5 \cdot 10^{3}$ & - & - & 1.5 \\
\hline 15 & - & $7.7 \cdot 10^{5}$ & - & - & 2.0 \\
\hline 25 & - & $1.0 \cdot 10^{6}$ & - & - & 3.5 \\
\hline 35 & - & $3.4 \cdot 10^{7}$ & - & - & 5.0 \\
\hline \multicolumn{6}{|c|}{ Tomato samples treated with Bacillus subtilis } \\
\hline $\begin{array}{c}0 \\
\text { (background) }\end{array}$ & - & $1.2 \cdot 10^{1}$ & - & - & - \\
\hline 3 & - & $8.5 \cdot 10^{1}$ & - & - & - \\
\hline 5 & - & $2.2 \cdot 10^{2}$ & - & - & - \\
\hline 7 & - & $5.9 \cdot 10^{2}$ & - & - & - \\
\hline 15 & - & $9.2 \cdot 10^{2}$ & - & - & - \\
\hline 25 & - & $1.1 \cdot 10^{3}$ & - & - & - \\
\hline 35 & - & $2.8 \cdot 10^{4}$ & - & - & - \\
\hline \multicolumn{6}{|c|}{ Tomato samples treated with Lactobacillus rhamnosus } \\
\hline $\begin{array}{c}0 \\
\text { (background) }\end{array}$ & - & $1.3 \cdot 10^{1}$ & - & - & - \\
\hline 3 & - & $8.9 \cdot 10^{1}$ & - & - & - \\
\hline
\end{tabular}


Table 1. Continued

\begin{tabular}{|c|c|c|c|c|c|}
\hline 5 & - & $2.1 \cdot 10^{2}$ & - & - & - \\
\hline 7 & - & $6.8 \cdot 10^{2}$ & - & - & - \\
\hline 15 & - & $8.3 \cdot 10^{2}$ & - & - & - \\
\hline 25 & - & $1.4 \cdot 10^{3}$ & - & - & - \\
\hline 35 & - & $1.1 \cdot 10^{4}$ & - & - & - \\
\hline \multicolumn{6}{|c|}{ Tomato samples treated with Pseudomonas putida } \\
\hline $\begin{array}{c}0 \\
\text { (background) }\end{array}$ & - & $1.7 \cdot 10^{1}$ & - & - & - \\
\hline 3 & - & $7.7 \cdot 10^{1}$ & - & - & - \\
\hline 5 & - & $1.8 \cdot 10^{2}$ & - & - & - \\
\hline 7 & - & $4.3 \cdot 10^{2}$ & - & - & - \\
\hline 15 & - & $6.2 \cdot 10^{2}$ & - & - & - \\
\hline 25 & - & $2.4 \cdot 10^{3}$ & - & - & - \\
\hline 35 & - & $5.7 \cdot 10^{4}$ & - & - & - \\
\hline \multicolumn{6}{|c|}{ Tomato samples treated with Psychrobacter immobilis } \\
\hline $\begin{array}{c}0 \\
\text { (background) }\end{array}$ & - & $1.2 \cdot 10^{1}$ & - & - & - \\
\hline 3 & - & $8.7 \cdot 10^{1}$ & - & - & - \\
\hline 5 & - & $2.7 \cdot 10^{2}$ & - & - & - \\
\hline 7 & - & $5.9 \cdot 10^{2}$ & - & - & - \\
\hline 15 & - & $8.6 \cdot 10^{2}$ & - & - & - \\
\hline 25 & - & $2.4 \cdot 10^{3}$ & - & - & - \\
\hline 35 & - & $4.1 \cdot 10^{4}$ & - & - & - \\
\hline \multicolumn{6}{|c|}{ Tomato samples treated with bioconservative nisin } \\
\hline $\begin{array}{c}0 \\
\text { (background) }\end{array}$ & - & $1.5 \cdot 10^{2}$ & - & - & - \\
\hline 3 & - & $3.8 \cdot 10^{2}$ & - & - & - \\
\hline 5 & - & $1.1 \cdot 10^{3}$ & - & - & - \\
\hline 7 & - & $1.6 \cdot 10^{3}$ & - & - & - \\
\hline 15 & - & $4.9 \cdot 10^{3}$ & - & - & - \\
\hline 25 & - & $3.2 \cdot 10^{4}$ & - & - & 1.1 \\
\hline 35 & - & $2.3 \cdot 10^{5}$ & - & - & 2.5 \\
\hline
\end{tabular}

Analysis of the results of studying dynamics of microbiological parameters of perishable food (fresh tomatoes), presented in Table 1, shows that the control samples (fresh tomatoes without preservative processing) on the 15 th day of storage at $4 \pm 2{ }^{\circ} \mathrm{C}$ exceeds such an indicator as QMA\&OAMO, on the 5th day, yeast already detected, whose content significantly increased by the end of the experiment. It was also found that treatment of perishable foods (fresh tomatoes) with known bioconservative nisin (food additive E234) can reduce their surface development of mesophilic aerobic and facultatively anaerobic microorganisms, their content $\left(2.0 \cdot 10^{5} \mathrm{CFU} / \mathrm{g}\right)$ exceeds the allowable value only for 35 days of storage. The activity of yeasts and molds on the surface of tomatoes treated with Nisin is reduced compared with the control.

Table 1 shows that the new isolated microorganisms synthesizing bacteriocins exhibit the highest bioconservation efficiency compared to nisin and control. It was shown that QMA\&OAMO does not exceed the maximum permissible value even at 35 days of storage, yeast and molds, E. coli group bacteria in $1.0 \mathrm{~g}$ and pathogenic microorganisms, including $L$. 
monocytogenes and Salmonella bacteria in $10.0 \mathrm{~g}$ were not detected in any of the tested samples of perishable food (fresh tomatoes).

The results of study of organoleptic properties of perishable foods (fresh tomatoes) treated with selected strains of microorganisms (Bacillus subtilis, Lactobacillus rhamnosus, Pseudomonas putida and Psychrobacter immobilis) are presented in Table 2.

Table 2. Results of the study of organoleptic properties of minimally processed food.

\begin{tabular}{|c|c|}
\hline Indicator name & Indicator value \\
\hline \multicolumn{2}{|c|}{$\begin{array}{c}\text { Fresh tomatoes treated with selected strains of microorganisms } \\
\text { (Bacillus subtilis, Lactobacillus rhamnosus, Pseudomonas putida and Psychrobacter immobilis) }\end{array}$} \\
\hline Appearance & $\begin{array}{l}\text { Fruits are fresh, free from harm, clean, healthy, undamaged } \\
\text { by pests, dense, typical shape, no mechanical damage or } \\
\text { sunburn }\end{array}$ \\
\hline Taste and smell & $\begin{array}{l}\text { Characteristic of the botanical variety, with no extraneous } \\
\text { taste or odor }\end{array}$ \\
\hline
\end{tabular}

As a result of the study of organoleptic quality indicators of perishable foods (fresh tomatoes), treated with selected strains of microorganisms (Bacillus subtilis, Lactobacillus rhamnosus, Pseudomonas putida and Psychrobacter immobilis), stored for 35 days at $4 \pm 2$ ${ }^{\circ} \mathrm{C}$ (Table 2) revealed that fresh tomatoes on the 35th day keep fresh, the fruit is clean, excessive moisture of fruits is not observed. Also fresh tomatoes were characterized by an edible degree of maturity. The taste and smell of the tomatoes were consistent with the botanical variety, while no extraneous taste and smell were observed.

\section{Conclusions}

Thus, the results of study of organoleptic indicators of the quality of perishable food (fresh tomatoes), treated with selected strains of microorganisms (Bacillus subtilis, Lactobacillus rhamnosus, Pseudomonas putida and Psychrobacter immobilis), stored for 35 days at $4 \pm 2$ ${ }^{\circ} \mathrm{C}$ indicate that treatment with selected strains of microorganisms (Bacillus subtilis, Lactobacillus rhamnosus, Pseudomonas putida and Psychrobacter immobilis) has no effect on organoleptic parameters of perishable food products (fresh tomatoes).

\section{Acknowledgements}

This paper was partially funded by the Russian Foundation for Basic Research (Contract No. 19-316-60002\19).

\section{References}

1. M. S. Tapia, S. M. Alzamora, J. Chirife, Water activity in foods: Fundamentals and applications, 4 (2020)

2. A. Tevenson, J. A. Cray, J. P. Williams, R. Santos, R. Sahay, N. Neuenkirchen, C. D. McClure, I. R. Grant, J. D. Houghton, J. P. Quinn, D. J. Timson, ISME J, 9 (2015)

3. X. Wang, A. Selvam, M. Chan, J.W. Wong, Bioresour., 147 (2013)

4. A. Valero, M. Y. Rodríguez, G. D. Posada-Izquierdo, F. Pérez-Rodríguez, E. Carrasco, R. M. García-Gimeno, Significance, Prevention and Control of Food Related Diseases, 13 (2016)

5. V. Velázquez-Ordoñez, B. Valladares-Carranza, E. Tenorio-Borroto, M. TalaveraRojas, J. A. Varela-Guerrero, J. Acosta-Dibarrat, F. Puigvert, L. Grille, Á.G. Revello, L. 
Pareja, Nutrition in Health and disease-our challenges Now and Forthcoming time, 16 (2019)

6. T. Møretrø, S. Langsrud, Comprehensive Reviews in Food Science and Food Safety, 16 (2017)

7. R. Margesin, F. Schinner, Agronomy, 9 (2019)

8. E. M. Johnson, D. Y. G. Jung, D. Y. Y. Jin, D. R. Jayabalan, D. S. H. Yang, J. W. Suh, Crit Rev Food Sci Nutr, 58 (2018)

9. S. A. Cichello, Food Sci. Technol, 52 (2015)

10. C. J. Doyle, D. Gleeson, K. Jordan, T. P. Beresford, R. P. Ross, G. F. Fitzgerald, P. D. Cotter, Int. J. Food Microbiol, 197 (2015)

11. A. E. Yousef, V. M. Balasubramaniam, Food microbiology: Fundamentals and frontiers, $6(2012)$ 